\title{
Role for TGF- $\beta$ superfamily signaling in telencephalic GABAergic neuron development
}

\author{
Mario Maira • Jason E. Long • Amie Y. Lee • \\ John L. R. Rubenstein • Stefano Stifani
}

Received: 14 August 2009 / Accepted: 12 October 2009/Published online: 27 November 2009

(C) The Author(s) 2009. This article is published with open access at Springerlink.com

\begin{abstract}
Signaling mechanisms mediated by the Transforming Growth Factor- $\beta$ (TGF- $\beta$ ) superfamily regulate a variety of developmental processes. Here we show that components of both bone morphogenetic protein/growth differentiation factor and TGF- $\beta$ /activin/Nodal branches of TGF- $\beta$ superfamily signaling are expressed in the developing subpallium. Furthermore, Smad proteins, transcriptional effectors of TGF- $\beta$ signaling, are co-expressed and physically interact in the basal ganglia with Dlx homeodomain transcription factors, which are critical regulators of the differentiation, migration and survival of telencephalic GABAergic neurons. We also show that Dlx and Smad proteins localize to promoters/enhancers of a number of common telencephalic genes in vivo and that Smad proteins co-activate transcription with Dlx family members, except with certain mutated human DLX proteins identified in autistic individuals. In agreement with these observations, expression of dominantnegative Smads in the developing basal ganglia phenocopies the cell migration defects observed in $D l \times 1 / 2$-deficient mice. Together, these results suggest that TGF- $\beta$ superfamily signaling plays a role in telencephalic GABAergic neuron development through functional interactions with Dlx transcription factors.
\end{abstract}

Electronic supplementary material The online version of this article (doi:10.1007/s11689-009-9035-6) contains supplementary material, which is available to authorized users.

M. Maira $\cdot$ S. Stifani $(\bowtie)$

Centre for Neuronal Survival, Montreal Neurological Institute,

McGill University,

3801 rue University,

Montreal, Quebec H3A 2B4, Canada

e-mail: stefano.stifani@mcgill.ca

M. Maira $\cdot$ J. E. Long • A. Y. Lee · J. L. R. Rubenstein Department of Psychiatry and the Nina Ireland Laboratory of Developmental Neurobiology,

University of California at San Francisco,

1550 4th Street, 2nd Floor South, Room GD 282,

San Francisco, CA 94158-2324, USA
Keywords Basal ganglia - Dlx · GABA · Interneurons · Smad $\cdot$ TGF- $\beta$

\section{Introduction}

Neurotransmitter subtype specification in the developing forebrain depends in part on the temporal and spatial coordinates of local neuronal progenitor/precursor cells. These coordinates are achieved through the induction of specific sets of transcription factors in response to a variety of extrinsic cues. Understanding the intrinsic molecular mechanisms underlying precursor cell diversity is essential to understanding the genesis of the forebrain.

In the developing telencephalon, the majority of gammaaminobutyric acid (GABA)-ergic interneurons arise from progenitor zones [ventricular (VZ) and subventricular (SVZ) zones] within the lateral, medial and caudal ganglionic eminences (LGE, MGE and CGE, respectively) of the basal ganglia anlage (subpallium). Newly generated GABAergic neurons exit the SVZ of these eminences and either radially migrate into the basal ganglia, where they largely differentiate into projection neurons, or tangentially migrate to dorsal structures of the pallium such as the cortex, hippocampus and olfactory bulb, where they differentiate into different subclasses of interneurons (Marin and Rubenstein 2003; Wonders and Anderson 2006; Ayala et al. 2007].

Four members of the mouse Dlx protein family (Dlx1, 2, 5 and 6), part of the Antennapedia class of non-Hox homeodomain transcription factors, are expressed in the embryonic subpallium (Panganiban and Rubenstein 2002). Within this region, their expression overlaps with that of Gad65 and Gad67, genes encoding different forms of the rate-limiting enzyme required for production of GABA from glutamate. In $D l \times 1 / 2^{-/-}$double mutant mice, the tangential migration of GABAergic interneurons into pallial structures is nearly extinguished and neuronal 
precursors accumulate in the SVZ of the MGE and CGE (Anderson et al. 1997a, b, 2001; Yun et al. 2002; Long et al. 2007). These findings show that $D l x$ function is essential to the correct differentiation and migration of GABAergic interneurons.

Currently, little is known about the signaling pathways that modulate Dlx activity. In that regard, recent studies in non-neural cells have suggested the existence of functional interactions between Dlx proteins and Smad transcription factors, which are critical mediators of transforming growth factor- $\beta$ (TGF- $\beta$ ) superfamily signaling pathways (Chiba et al. 2003; Berghorn et al. 2006). TGF- $\beta$ superfamily members, including activin, bone morphogenetic protein (BMP), growth differentiation factor (GDF), Nodal, and TGF- $\beta$ proteins, are secreted molecules that regulate an array of biological functions in many cell types (Shi and Massague 2003; Derynck and Zhang 2003; Massague et al. 2005). They act by stimulating specific membrane serine/ threonine receptor complexes, the activin-like kinase receptors, resulting in the phosphorylation and activation of regulatory Smads (R-Smads). Smads 1, 5 and 8 are mainly activated by BMP and GDF receptors, while Smads 2 and 3 are substrates for TGF- $\beta$, activin and Nodal receptors. Once activated, R-Smads accumulate in the nucleus where they associate with Smad4, a common partner for all RSmads, to form transcription complexes. R-Smad:Smad4 complexes regulate transcription of a variety of genes through recruitment of other transcription factors, including coactivators or corepressors (Shi and Massague 2003; Derynck and Zhang 2003; Massague et al. 2005).

Here we describe results that suggest an important role for TGF- $\beta$ superfamily signaling in the development of telencephalic GABAergic neurons. Moreover, we provide in vivo evidence that Dlx and R-Smad proteins are coexpressed, physically interact, and localize to Dlx-regulated enhancers/promoters in the developing subpallium. Our results show further that Dlx proteins synergistically activate transcription from the promoter of a Dlx target gene. Together, these results suggest that TGF- $\beta$ superfamily signaling and Dlx homeoproteins work together to promote telencephalic GABAergic neuron development.

\section{Materials and methods}

DNA plasmids

The reporter plasmid containing the $L a c Z$ gene driven by the mouse Dlx5/6 intergenic enhancer-i (mI56i-LacZ) (Zerucha et al. 2000) was provided by Dr. Mark Ekker (University of Ottawa, Ottawa, ON). Vectors for expression of FLAG epitope-tagged human DLX2 and DLX5 were obtained by cloning the complete human cDNA sequences into $\mathrm{pCAGGS/ES}$, a chicken $\beta$-actin promoter expression vector (Stuhmer et al. 2002a, b), using PCR primers containing the sequence of the FLAG epitope at the Nterminus. Expression vectors for the DLX2 (Ser7, Glu-Lys, and Ala-Thr) and DLX5 (Ser-Pro and Ser-Arg) mutant proteins identified in autistic patients were obtained using the QuickChange site-directed mutagenesis kit (Stratagene, La Jolla, CA). Plasmids pCAGGS-Dlx1 and pCAGGS-GFP were described elsewhere (Stuhmer et al. 2002a, b). Plasmids pCMV5B/FLAG-Smad1, pFLAG-Smad2, and pSmad4-HA (Attisano et al. 1996; Macias-Silva et al. 1996) were gifts from Drs. Jeffrey Wrana and Liliana Attisano (University of Toronto, Toronto, ON). Dominant negative mutant forms of Smad1, Smad2 and Smad4 (Zhang et al. 1996, 1998) were provided by Dr. Rik Derynck (UCSF, San Francisco, CA).

\section{Microarray analysis}

RNA was extracted from embryonic stage (E) 15.5 basal ganglia dissected from either wild type or $D l \times 1 / 2^{-/-}$ mutants. Total RNA was isolated using the Absolutely RNA Miniprep kit (Stratagene). Twenty micrograms of pooled RNA from each genotype was used. Hybridization to Affymatrix 4302.0 microarrays of the amplified and labeled cDNA was performed by the NIH Neuroscience Microarray Consortium (http://arrayconsortium.tgen.org/ np2/home.do).

\section{Animal procedures}

Animal procedures were conducted in accordance with the guidelines of the Canadian Council for Animal Care and were approved by the Montreal Neurological Institute Animal Care Committee. Pregnant females were anesthetized in a $\mathrm{CO}_{2}$ chamber and euthanized by cervical dislocation. E15.5 embryos were recovered and their brains dissected and fixed with $4 \%$ paraformaldehyde in phosphate-buffered saline. After fixation, brains were cryoprotected by immersion in 30\% sucrose, frozen-embedded in Tissue-Tek O.C.T. compound (Sakura Finetek U.S.A., Torrance, CA) and stored at $-80^{\circ} \mathrm{C}$. Frozen tissues were cryostat sectioned at $20 \mu \mathrm{m}$ and mounted onto SuperFrost Plus slides (Fisher, Pittsburgh, PA).

In situ hybridization

In situ hybridization experiments were performed using digoxigenin-labeled riboprobes on frozen sections as described on the Rubenstein lab website (http://www.ucsf. $\mathrm{edu} / \mathrm{j}$ lrrlab/protocols.html), using the following probes: Dlx2, Gad67 (provided by Dr. Brian Condie, University of Georgia, Athens, Georgia), Gdf11 (provided by Dr. Alexandra 
Joyner, Memorial Sloan Kettering Cancer Institute, New York, NY), ActRIIb (provided by Dr. Seung Kim, Stanford University, Stanford, CA) and BMPR1A (provided by Dr. Steve Harris, University of Texas Health Science Center at San Antonio, San Antonio, TX) (Bulfone et al. 1993; Feijen et al. 1994; Nakashima et al. 1999; Maddox and Condie 2001).

Immunohistochemistry

Analysis of E12.5 and E16.5 frozen sections was performed as described previously (Marin et al. 2000), except that sections were heated for $30 \mathrm{~min}$ at $60^{\circ} \mathrm{C}$ in a $10 \mathrm{mM}$ sodium citrate buffer. The following primary polyclonal antibodies were used either alone or in combination: rabbit antiphosphorylated Smad2 (1:250; Millipore, Billerica, MA; catalog No. AB3849) and guinea pig anti-Dlx2 (Kuwajima et al. 2006) $(1: 5,000$; kindly provided by Dr. Kazuaki Yoshikawa, Osaka University, Osaka, Japan). The following secondary antibodies were used: Alexa Fluor 488 goat antirabbit IgG $(\mathrm{H}+\mathrm{L})$ (1:1000; Invitrogen, Carlsbad, CA; product No. A-11008), Cy3 AffiniPure $\mathrm{F}\left(\mathrm{ab}^{\prime}\right) 2$ Fragment Goat Anti-Guinea Pig IgG $(\mathrm{H}+\mathrm{L})(1: 500$, Jackson ImmunoResearch, West Grove, PA; code No. 106-166-003).

\section{Chromatin immunoprecipitation}

Cross-linked protein-DNA complexes from dissected E15.5 telencephalon were obtained as described previously (Zhou et al. 2004). Approximately $1-2 \times 10^{7}$ dissociated cells were cross-linked with $1 \%$ paraformaldehyde for $2 \mathrm{~h}$ at room temperature in the presence of protease inhibitors. Chromatin immunopreciptation was then performed using the Upstate Biotechnology (Millipore) Chromatin Immunoprecipitation Assay Kit (Cat. No. 17-295) following the manufacturer's instructions. The following antibodies were used for immunoprecipitation: anti-FLAG M2 (Sigma, St. Louis, MO, Cat. No. F1804), anti-Dlx2 (Porteus et al. 1994), anti-Smad1 (A-4; Santa Cruz Biotechnology, Santa Cruz, CA, Cat. No. sc-7965 X), anti-phosphorylated Smad2 (Millipore; Cat. No. AB3849), anti-phosphorylated Smad2/3 (Ser 423/425) (Santa Cruz Biotechnology; Cat. No. sc-11769 X), and anti-Smad4 (C-20; Santa Cruz Biotechnology; Cat. No. sc-1909 X). The following oligonucleotides were used for polymerase chain reactions: Dlx1/ 2-F: 5'-CAGCTG CAAACCCAAGAGGG-3'; Dlx1/2-R: 5'-GCGCAGCAAATTTGGCTTTC-3'; D1x5/6-F: 5'GACATTGGGGA CAATTTAAGG-3'; Dlx5/6-R: 5'GCAATTTGTGTAT GAATAAC-3'; Arx-F: 5'-CAAG CATGTAATTAAGT GAGC-3'; Arx-R: 5'-CCACTGGT ACAATTGTCAAAT-3'; p21 distal-F: 5'-TATTGAATGTCGTGGTGGTGGTGA-3'; p21 distal-R: 5'ACAGCACAGCCTCAGGACCCCACT-3'.
Co-immunoprecipitation

For analysis of endogenous proteins, extracts from dissected E15.5 telencephalon were subjected to immunoprecipitation using either rabbit anti-phosphorylated Smad2, mouse antiFLAG, or rabbit anti-TrkB antibodies (Santa Cruz Biotechnology) (5 $\mu \mathrm{g}$ each per immunoprecipitation). Each immunoprecipitation contained $2 \mathrm{mg}$ of tissue extract in $1 \mathrm{ml}$ of Nonidet P-40 lysis buffer $(10 \mathrm{mM}$ Tris, $\mathrm{pH} 8.0$, $150 \mathrm{mM} \mathrm{NaCl}, 1 \%$ Nonidet P-40, $10 \%$ glycerol) supplemented with a protease inhibitor mixture (Roche Products, Welwyn Garden City, UK). Imunoprecipitates, together with $1 \%$ of input lysate, were subjected to Western blotting analysis with a chicken anti-Dlx2 antibody, a custom-made affinity-purified antibody raised against a peptide corresponding to amino acids 133 to 146 of mouse Dlx2 (NNEPDKEDLEPEIR) (Aves Lab, Tigard, OR).

\section{Transient transfection/transcription assays}

COS cells were transfected using a calcium phosphate precipitation protocol. In all cases, the total amount of transfected DNA was adjusted to $2.5 \mu \mathrm{g}$ per well. Assays were performed with $1.0 \mu \mathrm{g} /$ transfection of reporter construct mI56i-LacZ in the presence or absence of the effector plasmids indicated in the figure legends $(1.0 \mu \mathrm{g} /$ transfection $)$. In each case, $0.5 \mu \mathrm{g} /$ transfection of a reporter plasmid containing the luciferase gene under the control of the RSV promoter was used as a control for transfection efficiency. Twenty-four hours after transfection, cells were subjected to determination of $\beta$-galactosidase and luciferase activity as described (Maira et al. 2003). Results were expressed as mean values \pm S.D.

Organotypic slice culture and electroporation

Preparation of $250 \mu \mathrm{m}$ organotypic slice cultures from E12.5 forebrains and subsequent electroporation were performed as described (Stuhmer et al. 2002b). Focal expression of GFP and/or Smad1, 2 or 4 dominant negative mutants was achieved by pressure injecting the expression vectors $(5 \mu \mathrm{g} / \mu \mathrm{l})$ in the MGE or CGE. At least 16 slices were electroporated with each expression plasmids over 4 independent experiments. Electroporation was performed using 3 voltage pulses of $75 \mathrm{~V}$ with a duration of $5 \mathrm{~ms}$ using a GRASS SD9 stimulator with a $3 \mu \mathrm{F}$ capacitor placed in parallel to generate exponential decay of current intensity over time. Slices were photographed using a fluorescent microscope after 12, 36, 60 and $84 \mathrm{~h}$ in order to detect GFP expression. To monitor the extent of cell death in the electroporated samples, slices were cultured for $48 \mathrm{~h}$ after electroporation, followed by fixation in $4 \%$ paraformaldehyde, cryoprotection by immersion in $30 \%$ sucrose, 
and embedding in Tissue-Tek O.C.T. compound. Frozen slices were cryostat sectioned at $20 \mu \mathrm{m}$ and subjected to double-label immunofluorescence analysis using mouse anti-GFP (1:250; Novus Biologicals, Littleton, CO; catalog number NB-600597) and rabbit anti-active caspase 3 (1:500; BD Pharmingen, San Diego, CA; catalog number 557035) antibodies. Grayscale images were digitally adjusted to the appropriate green or red channels using Northern Eclipse software (Empix Imaging Inc., Missisauga, ON).

\section{Results}

Expression of TGF- $\beta$ superfamily signaling components in the developing basal ganglia

A microarray analysis was performed to determine $T G F-\beta$ pathway gene expression in the subpallium of E15.5 mouse embryos. The same analysis was also performed using Dlx1/2-deficient embryos (results are available at the NIH Neuroscience Microarray Consortium website http://array consortium.tgen.org/np2/home.do) (Long et al. 2009). We found that several components of TGF- $\beta$ superfamily signaling were expressed in control embryos (Table 1). These included members of both the BMP/GDF and TGF$\beta /$ activin/Nodal subfamilies. Most notably, transcripts expressing the common transcription factor Smad4, as well as Smad1/5 and Smad2 (from the BMP/GDF or TGF- $\beta$ branches, respectively) were present in E15.5 subpallium, and their expression levels were comparable to those of Dlxl, 2 and 5. Although the expression of some of those genes (notably Gdf5/15, ALK-3 and Smad3) was slightly affected in Dlx1/2 $2^{--}$mutants, most of them were unchanged in mutant embryos, suggesting that expression of most TGF- $\beta$ superfamily genes is not downstream of $D l x$ function (Table 1).

In situ hybridization experiments using coronal section through E15.5 mouse telencephalon were performed to confirm the microarray results and correlate the expression of selected TGF- $\beta$ signaling genes to that of genes expressed in the basal ganglia (Supplemental Fig. 1). Dlx2 expression was detected throughout most of the subpallial telencephalon, notably in both the LGE and MGE. Within these structures, Dlx2 was strongly expressed in the progenitor domains comprising both the VZ and the SVZ (Supplemental Fig. 1A-D). As previously reported (Stuhmer et al. 2002a, b), Gad67 expression closely resembled that of Dlx2, except that it was observed mostly in the SVZ and mantle zone (where postmitotic neurons are located) of the LGE and MGE (Supplemental Fig. 1E-H). Expression analysis of representative members of the $B M P /$ $G D F$ signaling pathways, including ligands $(G d f 11)$ and receptors (ActRIIb and BMPRIA), revealed overlapping
Table 1 Microarray analysis of the expression of $T G F-\beta$ superfamily components in the developing subpallium

Value WT Value $D l \times 1 / 2^{-/}$

\begin{tabular}{llrr}
\hline A) BMP/GDF $\rightarrow$ ALK $1 / 2 / 3 / 6 \rightarrow$ Smad & $1 / 5 / 8$ pathway & \\
Ligand & Gdfl0 & 63 & 55 \\
& Gdfl1 & 57 & 38 \\
& Gdfl5 & 56 & 16 \\
& Gdf2 & 46 & 35 \\
& Gdf3 & 46 & 20 \\
& Gdf9 & 42 & 44 \\
& Gdf5 & 30 & 12 \\
Receptor & BMP-RIA (ALK-3) & 300 & 491 \\
& ActRI (ALK-2) & 281 & 235 \\
& ActRII & 236 & 254 \\
& ActRIIB & 230 & 248 \\
& BMP-RIB (ALK-6) & 74 & 76 \\
& BMPRII & 82 & 93 \\
Smad & Smad4 & 2060 & 1837 \\
& Smad1 & 711 & 729 \\
& Smad5 & 239 & 205 \\
& Smad7 & 44 &
\end{tabular}

B) TGF- $\beta$ /activin Nodal $\rightarrow$ ALK4/5/7 $\rightarrow$ Smad $2 / 3$ pathway

\begin{tabular}{|c|c|c|c|}
\hline \multirow[t]{3}{*}{ Ligand } & TGF $\beta 1$ & 108 & 81 \\
\hline & TGF $\beta 2$ & 59 & 76 \\
\hline & TGF $\beta 3$ & 38 & 13 \\
\hline \multirow[t]{4}{*}{ Receptor } & TGF $\beta$-RI (ALK-5) & 638 & 706 \\
\hline & TGF $\beta$-RII & 36 & 25 \\
\hline & ActRII & 236 & 254 \\
\hline & ActRIIB & 230 & 248 \\
\hline \multirow[t]{4}{*}{ Smad } & Smad4 & 2060 & 1837 \\
\hline & Smad2 & 283 & 337 \\
\hline & Smad3 & 58 & 14 \\
\hline & Smad7 & 44 & 67 \\
\hline \multicolumn{4}{|c|}{ C) Dlx transcription factors } \\
\hline \multirow[t]{4}{*}{ Dlx } & Dlx1 & 1237 & 15 \\
\hline & Dlx2 & 287 & 8 \\
\hline & Dlx 5 & 706 & 71 \\
\hline & Dlx6 & 140 & 20 \\
\hline
\end{tabular}

Microarray gene expression analysis in the subpallium of E15.5 wild type and Dlx $1 / 2^{-/}$mutants. Shown are genes of the $B M P / G D F(A)$ and $T G F-\beta /$ activin/Nodal $(B)$ subfamilies. Each $T G F-\beta$ superfamily member whose expression value was greater than 30 was included (genes expressed at values $>30$ are generally detectable by in situ hybridization) (Long et al. 2009). $C$, analysis of $D l x$ gene expression.

expression with $D l x 2$ and Gad67 within the subpallium. $A c t R I I b$ and BMPRIA were strongly expressed in both the VZ and SVZ of the MGE and LGE (Supplemental Fig. $1 \mathrm{M}-\mathrm{T})$, similar to the $D l x 2$ subpallial expression. By contrast, Gdf11 was mainly expressed in the SVZ of the LGE and MGE, similar to the expression of Gad67 (Supplemental Fig. 1I-L). 
To determine whether Smad signaling is activated in the developing mouse basal ganglia, we subjected brain coronal sections to immunohistochemistry with antibodies against activated Smad2 (phosphorylated at serines 465 and 467). At both E12.5 (Fig. 1A-D; Supplemental Fig. 2) and E16.5 (Fig. 1E-K), phosphorylated Smad2 (pSmad2) immunoreactivity was observed in the LGE, MGE, and CGE, where it localized mostly to the VZ and SVZ, with less robust but detectable expression in the mantle zone. Importantly, we observed co-expression of $\mathrm{pSmad} 2$ and D1x2, detected using a previously described anti-Dlx2 antibody (Kuwajima et al. 2006), in those regions (Fig. 1C, G, and K,). Moreover, small numbers of cells co-expressing pSmad2 and Dlx2 were also observed in the lateral neocortex, along the trajectory normally occupied by tangentially migrating Dlx2-positive GABAergic neurons (Fig. 1D and K). Together, these findings provide evidence that the TGF- $\beta$ superfamily pathway is activated in precursor cells and immature neurons of the subcortical telencephalon that also express Dlx proteins.

Functional interaction between Dlx and Smad transcription factors

Previous studies have suggested that Dlx and Smad proteins interact in non-neural cells (Chiba et al. 2003; Berghorn et al. 2006). Based on our finding that Dlx and activated Smad expression overlaps in the developing basal ganglia, we tested if Smad factors might interact with Dlx homeoproteins in the developing telencephalon. E15.5 mouse embryo telencephalic extracts were subjected to immunoprecipitation with either anti-phosphorylated Smad2 or control antibodies, followed by Western blotting analysis with anti-Dlx2 antibodies. These studies showed that endogenous Dlx2 was co-immunoprecipitated with activated Smad2 (Fig. 2A, lane 4), but not when control antibodies were used (Fig. 2A, lanes 2 and 3). These results show that Dlx2 and activated Smad2 interact in vivo.

To determine whether Dlx5 can also interact with Smad2, co-immunoprecipitation studies were performed using extracts from COS cells transfected with constructs encoding epitope-tagged FLAG-Smad2 or HA-Smad4 in combination with FLAG-tagged human DLX5 (throughout this paper, "Dlx" is used to refer to mouse proteins and "DLX" to indicate human proteins). Immunoprecipitations using a rabbit antibody raised against DLX5 revealed that Smad2 co-immunoprecipitated with DLX5 (Supplemental Fig. 3). In agreement with previous reports (Chiba et al. 2003; Berghorn et al. 2006), no interaction between Smad4 and DLX5 was detected (Supplemental Fig. 3).

Chromatin immunoprecipitation studies using E15.5 telencephalon were performed next to determine whether both Dlx and Smad proteins would localize in vivo to the regulatory regions of genes regulated by Dlx factors (Zerucha et al. 2000; Ghanem et al. 2007; Colasante et al. 2008; Potter et al. 2009). Using a panel of different antiSmad antibodies and previously characterized Dlx2 antibodies (Zhou et al. 2004; Porteus et al. 1994), we found that Dlx2, Smad1, Smad2/3, and Smad4 were associated with the Dlx $1 / 2, D l x 5 / 6$ and Arx enhancers in the E15.5 telencephalon (Fig. 2B).

Transient transfection assays were then conducted to determine whether Dlx and Smad proteins would regulate together transcription from a telencephalic enhancer. COS cells were transfected with a plasmid containing a $L a c Z$ reporter gene under the control of the $D l \times 5 / 6$ intergenic enhancer (Zerucha et al. 2000) in combination with various DLX and/or Smad expression plasmids. DLX2, and also DLX1 and DLX5, activated transcription of the reporter gene 5-10 fold (Fig. 2C). Expression of Smad1, Smad2 or Smad4 alone had no significant effect on reporter gene expression, suggesting that Smad transcription factors do not directly bind the $D l \times 5 / 6$ enhancer or that they require the presence of transcriptional partners to activate transcription upon binding. However, when co-expressed in combination with DLX5, DLX2, and to a lesser degree DLX1, both Smad1 and Smad2 significantly enhanced DLX-dependent transcriptional activation, whereas Smad4 had little or no effect (Fig. 2C). We observed no increased DLX affinity for DNA in the presence of Smad in electrophoretic mobility shift assays (data not shown).

Taken together, these results indicate that Smad and Dlx proteins are co-expressed and interact in cells of the developing telencephalon. Moreover, they localize to enhancer/promoters of telencephalic genes in vivo, and can co-operatively activate transcription. These findings provide evidence that Smad and Dlx proteins functionally interact to promote activation of telencephalic gene expression in vivo.

Distinct effects of naturally occurring DLX mutations from autistic patients on Smad-dependent potentiation of DLX transcriptional activity

Previous evidence suggests a role for DLX proteins in human neuropsychiatry disorders, such as autism. For instance, mice lacking $D l x l$ exhibit loss of subsets of local cortical circuit neurons and develop epilepsy, a malady commonly seen in the autistic population (Cobos et al. 2005). In addition, the human $D L X$ bigene clusters are located on chromosomes 2q31.1 (DLX 1/2) and 7q21 (DLX $5 / 6$ ), which are both autism susceptibility loci as determined by independent linkage studies (Consortium IMGSoA 2001; Bacchelli et al. 2003; Hutcheson et al. 2003). Furthermore, sequencing of $D L X$ genes in autistic patients and non-autistic siblings led to the identification of 


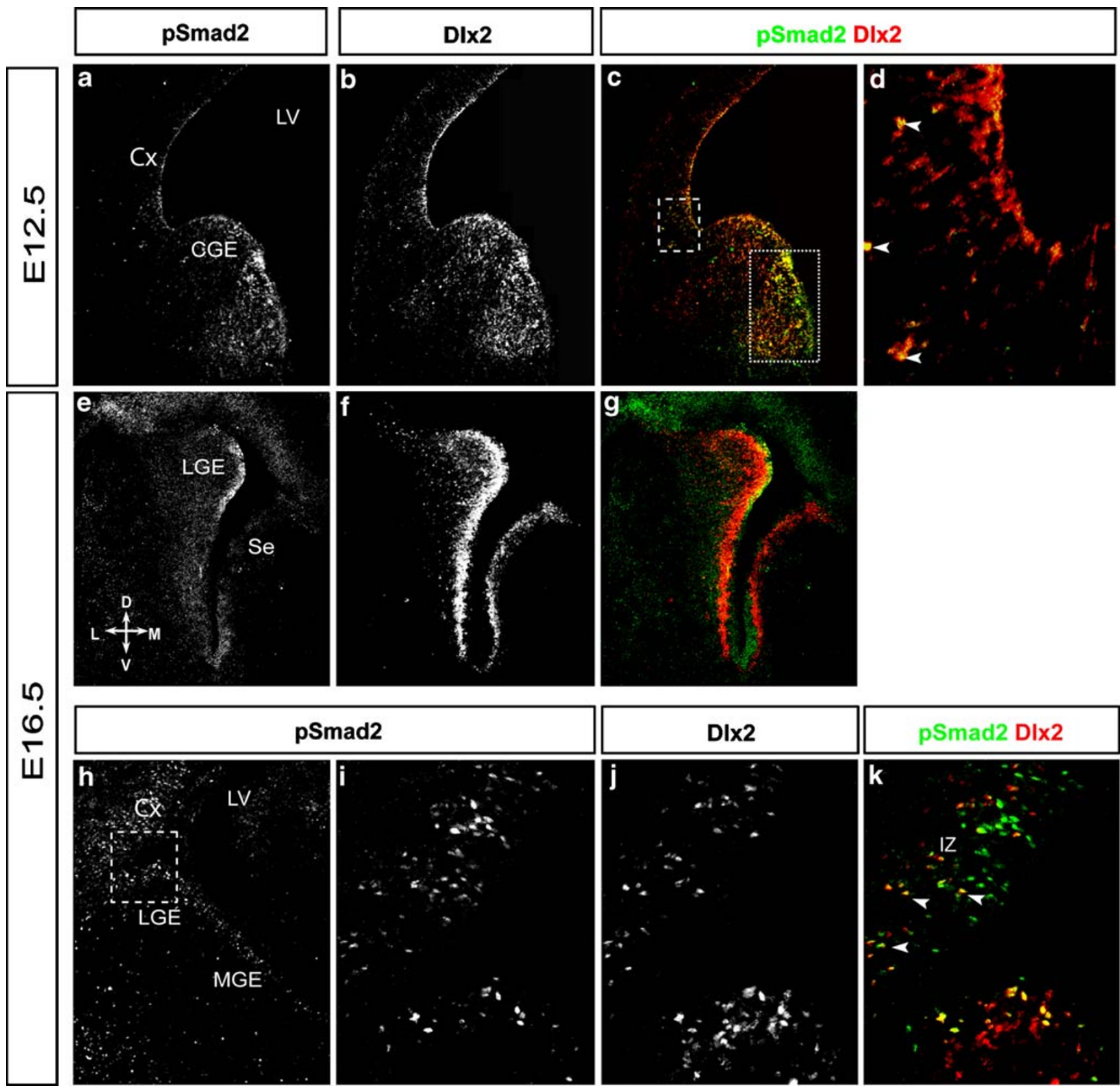

Fig. 1 Co-expression of activated Smad2 and Dlx2 in the developing basal ganglia. A-D, Double-labeling immunofluorescence analysis of the expression of phosphorylated Smad2 $(\mathrm{pSmad} 2)(\mathbf{A})$ and Dlx2 (B) in coronal hemisections of E12.5 forebrain at caudal telencephalic level. C, Merged pSmad2 and Dlx2 staining: overlapping expression (yellow color) is visible in many cells in the CGE (large rectangle). D, High-magnification view of the area enclosed by the small rectangle in (C): arrowheads point to cells co-expressing pSmad2 and Dlx2 in the neocortex. E-K, Expression of pSmad2 (E, H and $\mathbf{I})$ and Dlx2 (F and
$\mathbf{J})$ in coronal hemisections of E16.5 telencephalon at rostral $(\mathbf{E}-\mathbf{G})$ or mid-telencephalic $(\mathbf{H}-\mathbf{K})$ positions. Merged staining is shown in $(\mathbf{G}$ and $\mathbf{K})$. $\mathbf{I}-\mathbf{K}$, High-magnification views of the boxed area in $(\mathbf{H})$. Overlapping expression of pSmad2 and Dlx 2 was detected in the LGE and MGE, as well as in migrating GABAergic neurons in the neocortex (arrowheads in panel K). CGE, caudal ganglionic eminence; $\mathrm{Cx}$, neocortex; IZ, intermediate zone; LGE, lateral ganglionic eminence; LV, lateral ventricle; MGE, medial ganglionic eminence; Se, septum

To determine whether the DLX2 and/or DLX5 mutations characterized in autistic patients might affect the interaction between Smad and DLX proteins, we introduced those mutations into the human $D L X 2$ or $D L X 5$ cDNA sequences three non-synonymous mutations in DLX2 ("Ser7", "GluLys", and "Ala-Thr") and two in DLX5 ("Ser-Pro" and "Ser-Arg") in autistic individuals (Hamilton et al. 2005) (Fig. 3A). 
Fig. 2 Physical and functional interaction between Dlx and Smad transcription factors. A, In vivo co-immunoprecipitation. Extracts obtained from dissected E15.5 telencephalon were subjected to immunoprecipitation with anti-phosphorylated Smad2 (lane 4) or control (lane 2 and 3) antibodies, as indicated. Immunoprecipitates, together with $1 \%$ of input lysate (lane 1), were subjected to Western blotting with a chicken anti-Dlx2 antibody. The position of migration of the immunoglobulin light chain (IgG LC) is indicated. B, Chromatin immunoprecipitation. Protein-DNA complexes from dissected E15.5 telencephalon were subjected to immunoprecipitation with the indicated antibodies, followed by PCR with oligonucleotide primers specific for the Dlx $1 / 2, D l \times 5 / 6$ and Arx enhancers or the p $21^{\text {Cip } 1}$ distal promoter. Dlx2, Smad1, Smad2/3, and Smad4 were associated with the Dlx $1 / 2, D l \times 5 / 6$ and Arx enhancers, but not with the distal region of the $p 21^{C i p 1}$ promoter. Total genomic DNA was used as a positive control (Input). C, Transient transcription assays. The effect of Smad1, Smad2 or Smad4 on Dlx1-, Dlx2- and Dlx5-mediated transcriptional activity was assessed by co-transfecting COS cells with a LacZ reporter plasmid driven by the Dlx5/6 enhancer-i (mI56i$L a c Z$ ). Results are shown relative to the activity of the reporter alone and represent the means \pm the S.D. of at least four experiments performed in duplicates $(*, p<0.05$ using one-way analysis of variance with a Dunnett's post test). A reporter plasmid containing the luciferase gene under the control of the $R S V$ promoter was used as a control for transfection efficiency

by site-directed mutagenesis. All of the mutated proteins exhibited similar expression levels when transfected in COS cells (Fig. 3B). Moreover, in dose-dependent transient transfection/transcription assays, all DLX2 and DLX5 mutants retained the ability to activate transcription (Supplemental Fig. 4A). The DLX2 mutants exhibited a trend towards a stronger transcriptional activity than wild type DLX2, but this was not statistically significant. EMSA analysis indicated no alteration in DNA binding for any of the DLX mutants (Supplemental Fig. 4B).

The transcriptional activity of the DLX2 mutants was enhanced by Smad1 and Smad2, similarly to wild-type proteins (Fig. 3C). By contrast, both DLX5 mutants exhibited impaired functional interaction with Smad factors. More specifically, the transcriptional activity of the DLX5 Ser-Pro mutant was not potentiated by either Smad1 or Smad2, while the DLX5 mutant Ser-Arg was not responsive to Smad2-mediated transcriptional potentiation (Fig. 3C). Together, these results suggest that DLX mutations identified in autistic patients do not perturb DLX DNA binding and transcriptional activity but have different effects on DLX:Smad interactions.

Inhibition of tangential cell migration from the basal ganglia to the cortex by blockage of TGF- $\beta$ superfamily signaling

Dlx genes are essential for the proper migration of GABAergic interneurons from the subpallial SVZ to the neocortex (Anderson et al. 1997a, b, 2001). Smad and Dlx proteins are co-expressed in the basal ganglia and in cells located in the lateral neocortex, likely corresponding to a
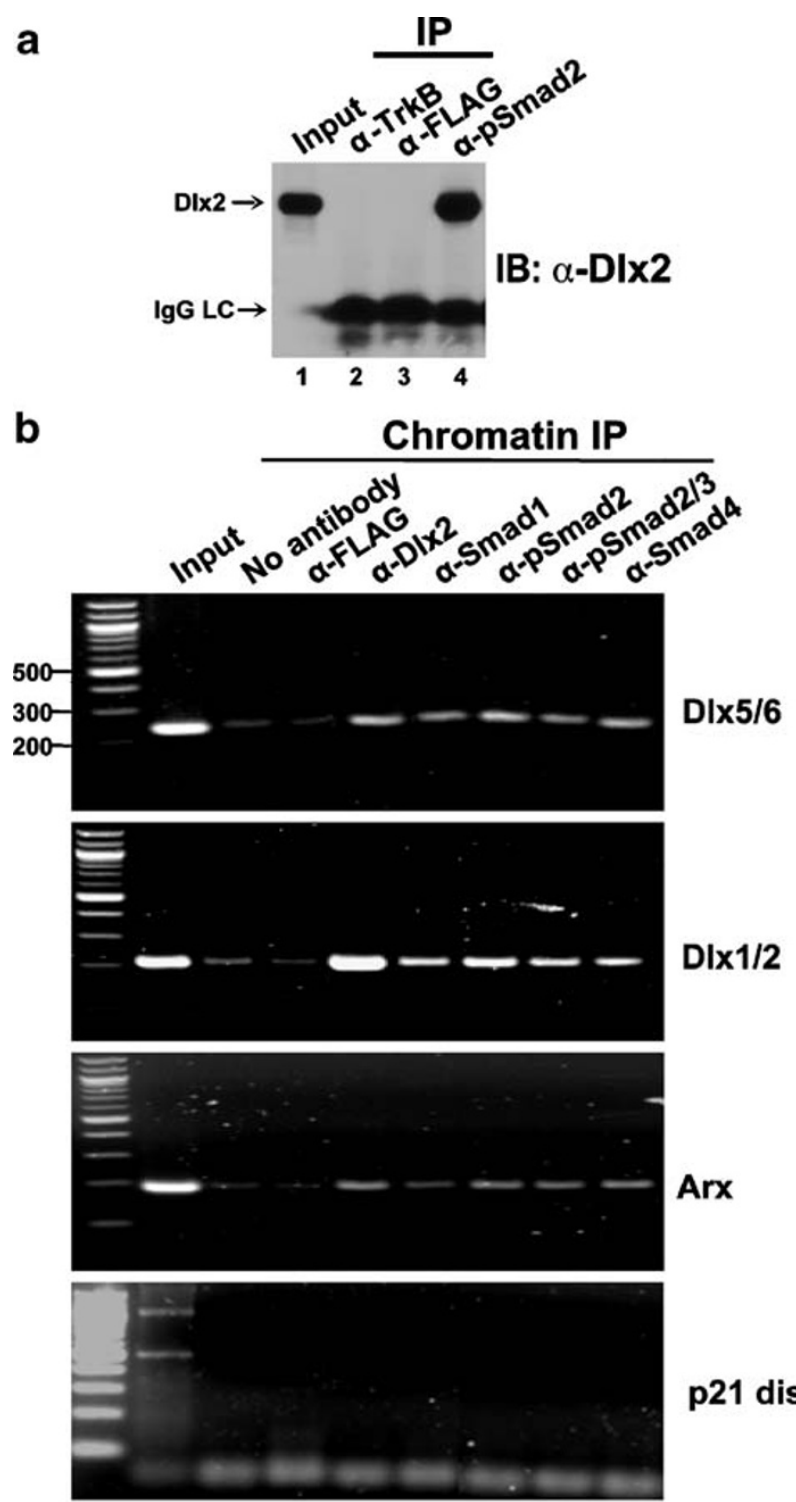

p21 distal

C

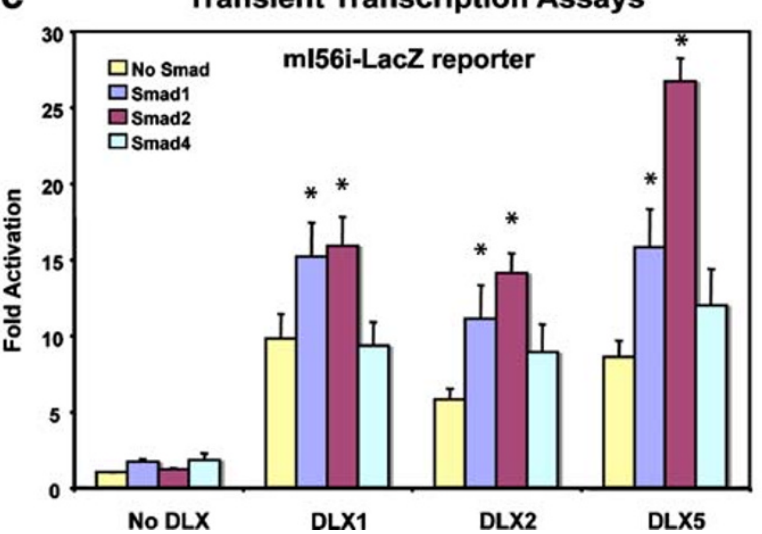

tangentially migrating GABAergic neurons (Fig. 1). Moreover, Smad and Dlx proteins interact in the developing telencephalon and localize to common DNA sequences in vivo (Fig. 2). Based on these observations, we examined 
a

DLX2 and DLX5 mutations in autistic individuals
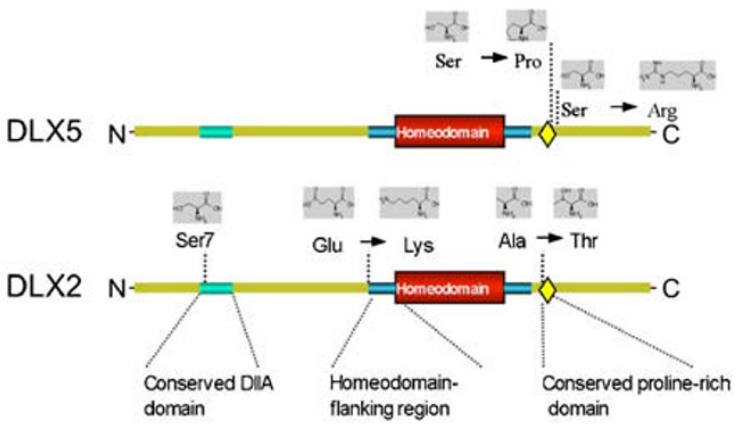

b Expression of wild type and mutant DLX proteins

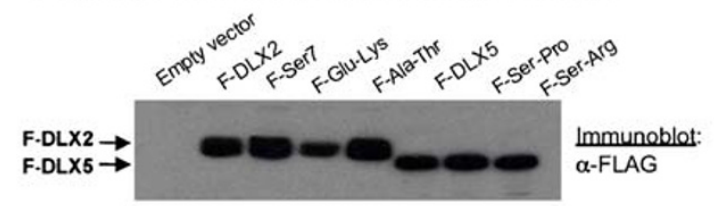

C Transient Transcription Assays

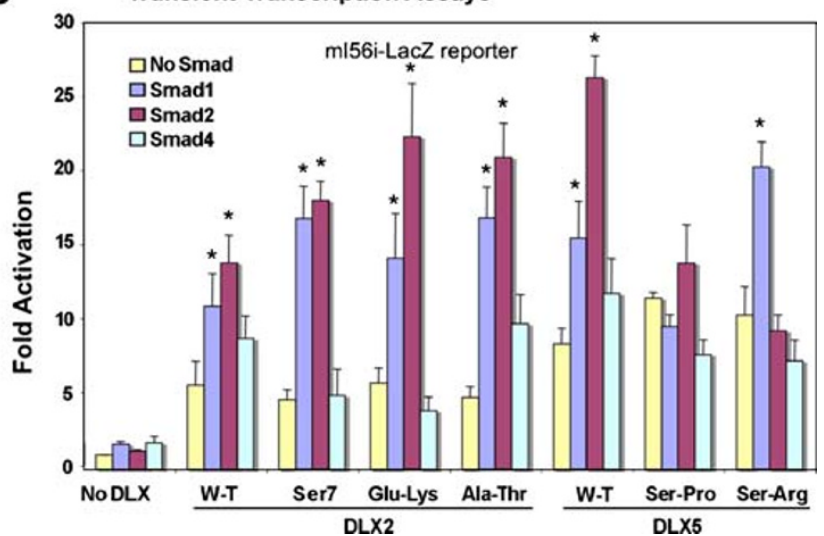

Fig. 3 Effect of Smad proteins on the transcriptional activity of mutated DLX proteins found in autistic individuals. A, Schematic representation of the location of the DLX2 and DLX5 mutations identified in autistic individuals. Note that all mutations occur in regions of homology between DLX proteins. The DLX2 serine insertion (Ser7) is in the DllA domain conserved in the DLX2/3/5 subgroup (green boxes), the DLX2 glutamic acid to lysine (Glu-Lys) mutation is in a conserved region flanking the homeodomain of the $D L X 2 / 3 / 5$ subgroup (blue boxes), while the DLX2 alanine to threonine (Ala-Thr) and both DLX5 serine to proline (Ser-Pro) and serine to arginine (Ser-Arg) mutations occur in a proline-rich domain conserved in all six mammalian DLX proteins (yellow boxes). B, Expression of wild type (WT) and mutant DLX proteins. COS cells were transfected with plasmids expressing the indicated proteins, followed by Western blot analysis with an anti-FLAG antibody. C, Transient transcription assays. COS cells were transfected with a $L a c Z$ reporter plasmid driven by the $D l x 5 / 6$ enhancer-i in the absence or presence of the indicated combinations of proteins. All DLX2 mutants behaved like wild type DLX2 in these assays in the absence or presence of Smad proteins. By contrast, Smad co-expression did not enhance DLX5 Ser-Pro-mediated transcriptional activity, while the DLX5 Ser-Arg mutant exhibited an impaired transcriptional interaction with Smad2. Results are shown relative to the activity of the reporter alone and represent the means \pm the S.D. of at least four experiments performed in duplicates $(*, p<0.05$ using one-way analysis of variance with a Dunnett's post test) whether TGF- $\beta$ signaling is involved in GABAergic interneuron development. More specifically, we tested if inhibition of TGF- $\beta$ signaling in the embryonic subcortical telencephalon would phenocopy the accumulation of immature interneurons in the SVZ of the MGE and CGE observed in Dlxl/2 null mutants. Organotypic slices from the brain of wild-type E12.5 mouse embryos were prepared from different levels of the rostro-caudal axis and focally electroporated in the VZ/SVZ of the MGE or CGE with a combination of dominant-negative Smad mutants (SmadDN) and GFP expression vectors. Controls involved electroporation of GFP alone ('control side'). Slices were then cultured and the tangential migration of the electroporated cells was monitored 12, 36, 60 and $84 \mathrm{~h}$ after electroporation.

To interfere with both branches of TGF- $\beta$ superfamily signaling, organotypic slices were electroporated with a previously described (Zhang et al. 1996, 1998) dominantnegative form of Smad4 (the obligatory partner for all RSmads). Compared to exogenous expression of GFP alone, expression of Smad4-DN in the MGE or CGE completely abrogated the tangential migration of the electroporated cells to the cortex (Fig. 4). Forced expression of Smad4-DN did not cause a notable increase in cell death, detected using an antibody against active caspase 3 (Supplemental Fig. 5). This result suggests that the impaired tangential migration caused by the expression of Smad4-DN was not the result of decreased survival of the electroporated cells. Similar experiments were performed using dominant-negative forms of Smad1 and Smad2 (Zhang et al. 1996, 1998) to specifically block either BMP/GDF subfamily or TGF- $\beta$ / activin/Nodal subfamily signaling, respectively. Expression of both Smad1-DN and Smad2-DN in the MGE or CGE also resulted in impaired tangential migration, compared to control conditions (Fig. 5). Each dominant-negative form alone had a weaker effect than Smad4-DN, consistent with only a partial inhibition of TGF- $\beta$ superfamily signaling in either case. Taken together with the results depicted in Figs. 1 and 2 , these findings provide evidence that TGF- $\beta$ superfamily signaling is important for neuronal cell migration from the subpallium to the cortex. Moreover, they suggest the existence of a functional interaction between Dlx and TGF- $\beta$ signaling pathways in the regulation of telencephalic GABAergic neuron development.

\section{Discussion}

Using a combination of expression studies and ex vivo electroporation assays, we provided evidence that both branches of TGF- $\beta$ signaling are active in developing ganglionic eminences and that dominant-negative inhibition of Smad activity in the basal ganglia impairs tangential 


\section{Smad4-DN}

Rostral

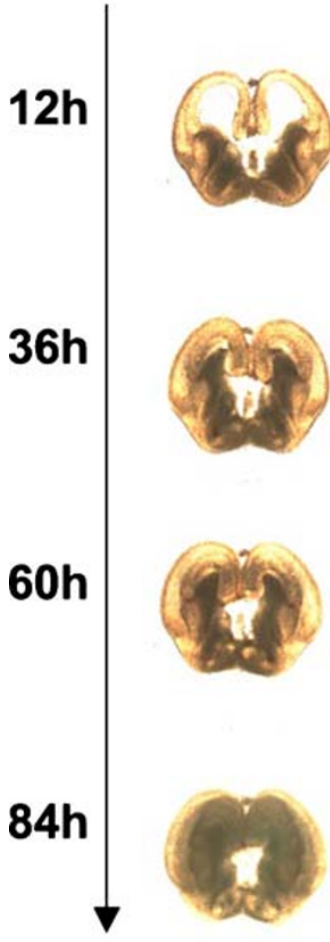

Bright Field
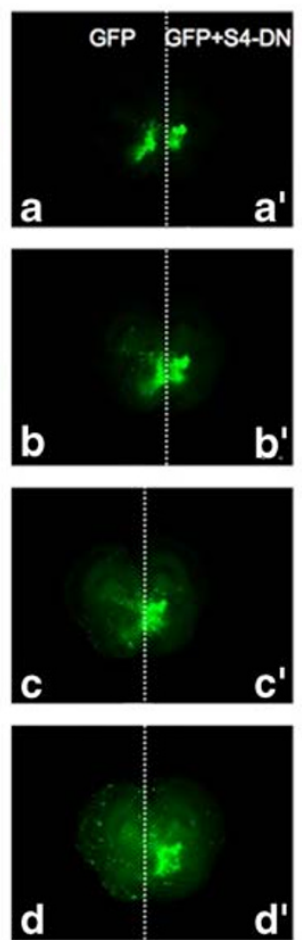

Fluorescence

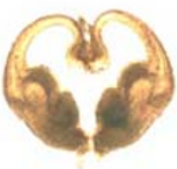

e
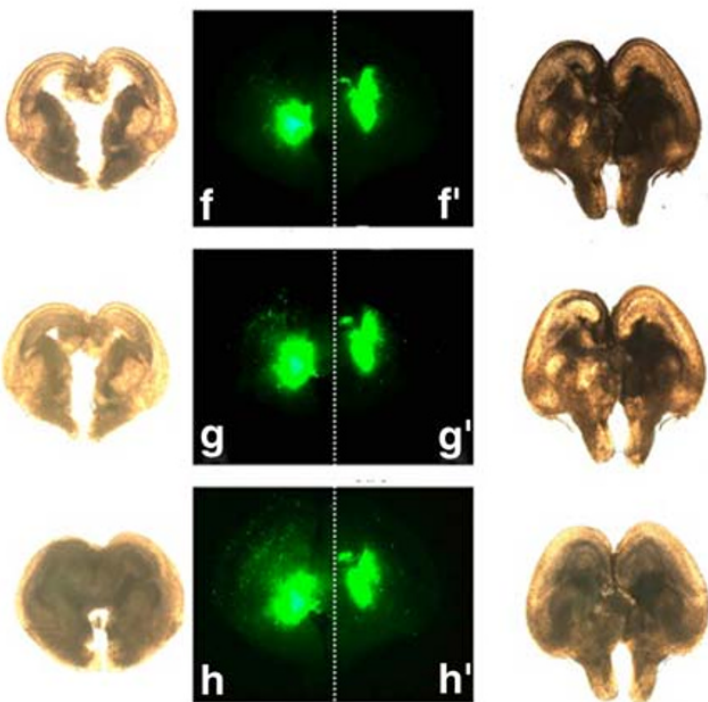

Fluorescence
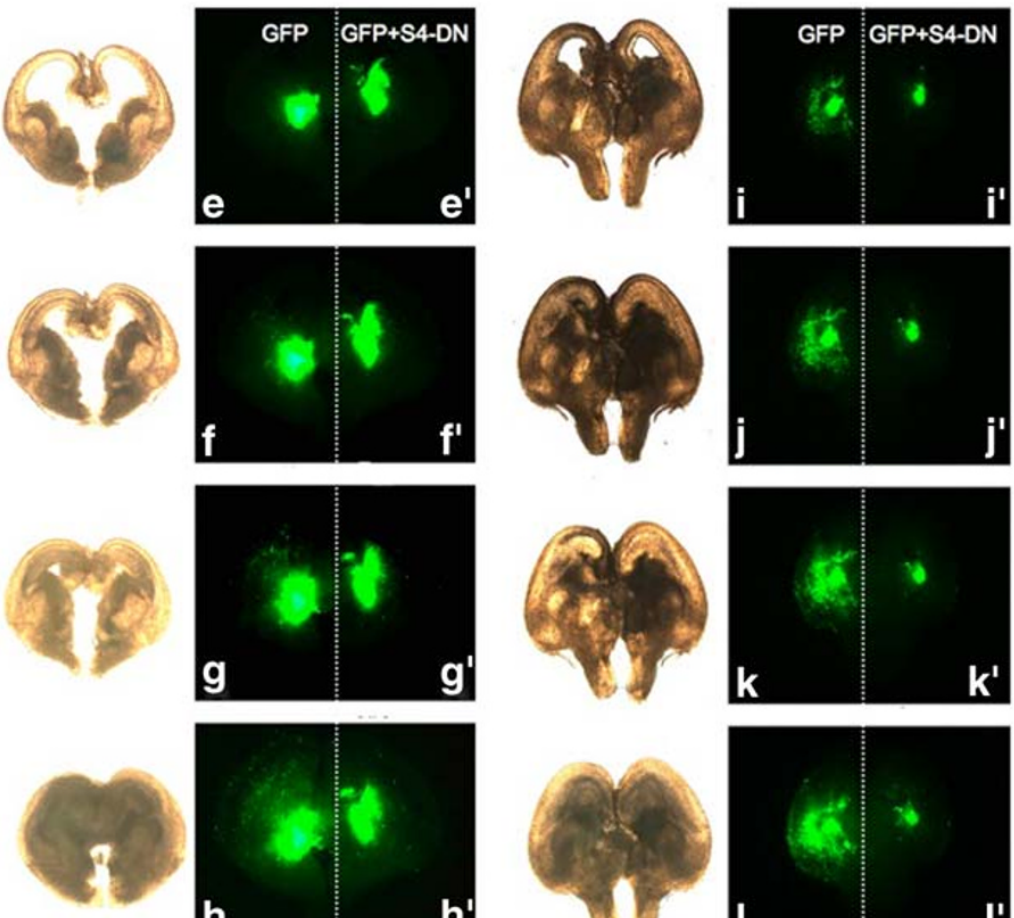

Bright Field

Fig. 4 Role for TGF- $\beta$ signaling in tangential migration of GABAergic interneurons in the developing telencephalon. Organotypic cultures of E12.5 forebrain slices from different levels of the rostrocaudal axis were focally electroporated into the MGE or CGE with a GFP expression vector alone (left hemisphere; panels a-1) or with a combination of GFP and dominant-negative Smad4 (Smad4-DN) (right hemisphere; shown

neuronal migration to the cortex. In agreement with the demonstration that blocking Smad signaling phenocopies the GABAergic interneuron migration defect observed in Dlx1/2-deficient mice, we also demonstrated that Dlx and Smad proteins are co-expressed, interact, and localize to common gene regulatory sequences in the developing telencephalon. Moreover, they co-activate transcription from a telencephalic enhancer in vitro. These results suggest a cross-talk between TGF- $\beta$ signaling and Dlx proteins during development of telencephalic GABAergic neurons.

Activation of TGF- $\beta$ signaling in the developing basal ganglia

TGF- $\beta$ signaling pathways perform critical roles during a variety of developmental processes, including functions important for brain patterning and differentiation (Liem et al. 1997; Crossley et al. 2001; Panchision et al. 2001; Hebert et al. 2002, 2003; Seoane et al. 2004; Fernandes et al. 2007). Several previous studies suggest roles for TGF- $\beta$ signaling in dorsal forebrain development. For instance, Bmp 2/4/5/6/7 are expressed in the embryonic dorsomedial telencephalon, a region that gives rise to the cortical hem and the choroid plexus. In this region, those BMP proteins induce Msxl and repress Foxgl gene expression, thus inhibiting progenitor cell proliferation (Furuta et al. 1997; Shimamura and Rubenstein 1997; Ohkubo et al. 2002). A role for BMP signaling in the dorsal telencephalon is also suggested by the conditional mutation of BMP receptors, which results in loss of the choroid plexus (Hebert et al. 2002, 2003; Fernandes et al. 2007). In contrast, relatively little is known about the role of the TGF- $\beta$ pathway during development of the basal ganglia and GABAergic neurons.

To begin to determine whether TGF- $\beta$ superfamily signaling is important for the development of the subpallium, we analyzed the basal ganglia RNA expression of components from both $T G F-\beta$ signaling sub-pathways, including ligands, receptors and Smad transcription factors. Our findings show that genes encoding several TGF- $\beta$ 


\section{A}

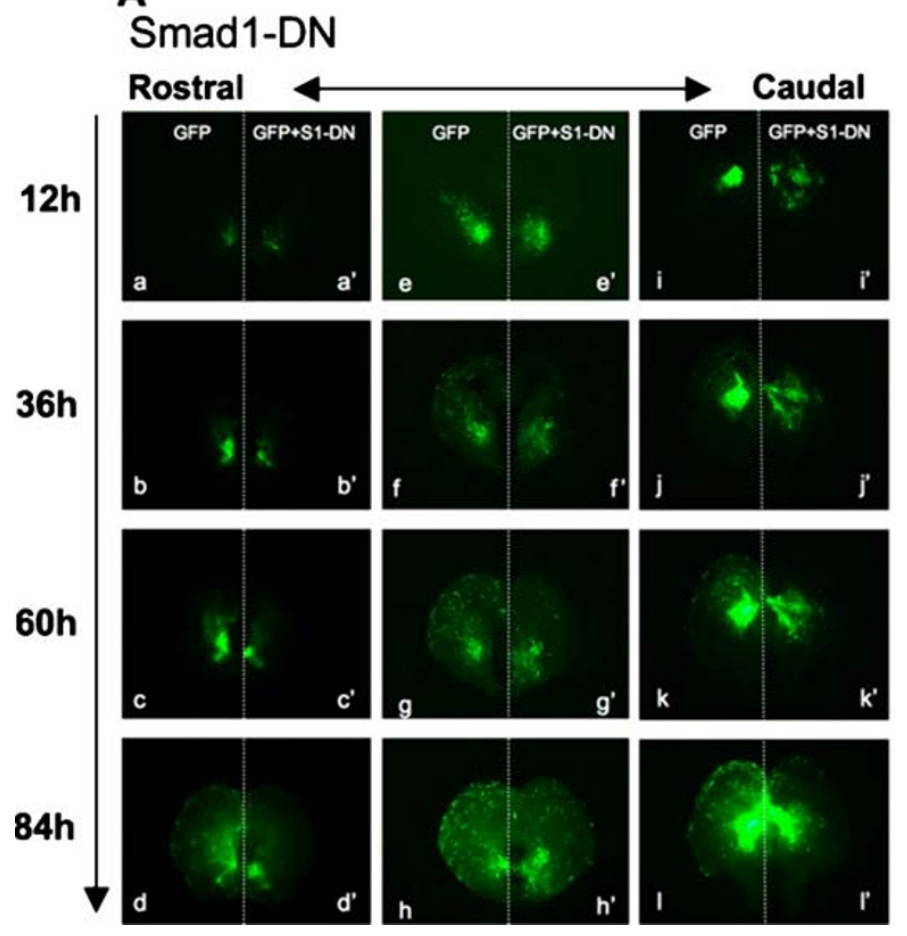

B

Smad2-DN
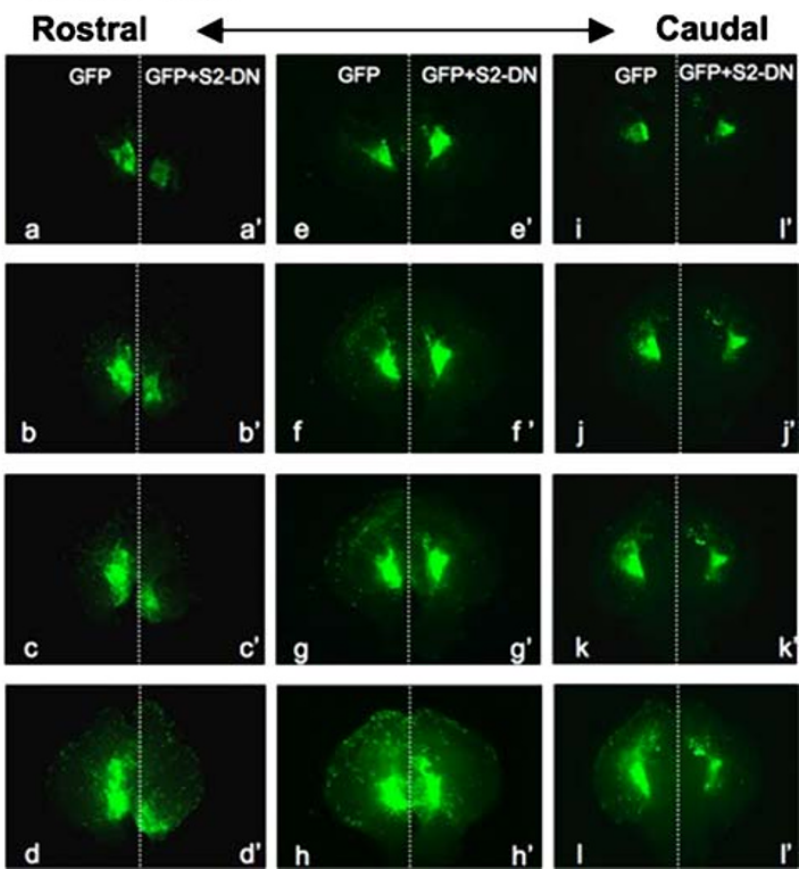

Fig. 5 Role for both branches of TGF- $\beta$ signaling in tangential migration of GABAergic interneurons in the developing telencephalon. Organotypic cultures of E12.5 forebrain slices from different levels of the rostrocaudal axis were focally electroporated into the MGE or CGE with a GFP expression vector alone (left hemisphere; panels a-1) or with a combination of GFP and dominant-negative Smad1 (Smad1-DN) (A) or dominant negative $\mathrm{Smad} 2(\mathrm{Smad} 2-\mathrm{DN})$ (B) (right hemisphere; shown in each case in panels $\left.\mathrm{a}^{\prime}-\mathrm{l}^{\prime}\right)$. Slices were photographed after 12, 36,60 and $84 \mathrm{~h}$ to visualize the tangential migration of GFPexpressing cells from the MGE or CGE. Decreased cell migration towards the neocortex was observed in the hemisphere electroporated with dominant-negative Smad forms superfamily ligands, including Gdf11, are expressed in the basal ganglia. This observation extends previous reports describing the forebrain expression of certain members of this secreted protein family, including $B m p 7$ (Tole et al. 2000), Bmp9 (Lopez-Coviella et al. 2006), and Bmp2/4/6 (Hattori et al. 1999; Gratacos et al. 2002). Our results also show that type I and type II receptors for both TGF- $\beta$ subpathways are expressed in the subpallium. This finding confirms previous reports showing that most BMP/GDF subfamily receptors are detected in the developing basal ganglia (Lopez-Coviella et al. 2006; Hattori et al. 1999; Gratacos et al. 2002). We also detected expression of Smad1, Smad5, Smad2, as well as Smad4, in the subpallium, where they exhibit expression levels similar to those of the $D l x$ genes. In contrast, Smad 3 and Smad7 appear to be only weakly expressed in the basal ganglia. Similar observations were made in septum-derived cells, albeit at different developmental stages (Lopez-Coviella et al. 2006).

We showed further that phosphorylated (activated) Smad1 (data not shown) and Smad2 (this study) are present in the developing basal ganglia. Importantly, phosphorylated Smad2 expression exhibits a regional and cellular overlap with Dlx2 expression in the subpallium, suggesting that Smad2 is activated in developing telencephalic GABAergic neuronal precursors that express Dlx2 (Anderson et al. 2001; Eisenstat et al. 1999). Certain Dlx2-positive cells did not appear to express activated Smad2. This observation could be due to the fact that activated Smad3 and/or Smad1/5 might be expressed in those cells and play a role similar to that of phosphorylated Smad2. Alternatively, Smad2 might not be phosphorylated in all cells expressing Dlx2. Importantly, we also observed the presence of cells co-expressing phosphorylated Smad2 and Dlx2 in the neocortex, likely corresponding to tangentially migrating interneurons, suggesting an involvement of TGF- $\beta$ signaling in tangential interneuron migration. Together, these findings correlate activated Smad2 expression with sequential stages of telencephalic GABAergic neuronal development.

Functional interaction between Dlx and Smad transcription factors

Prior to the present study, little was known about the molecular mechanisms underlying Dlx activity during basal ganglia development. Previous information was limited to the observation that Dlx and Msx1/Msx2 homeoproteins interact to mediate a mutual inhibition of their DNA binding activities and transcriptional functions (Panganiban 
and Rubenstein 2002; Zhang et al. 1997). In the present study, we tested the possibility of a cross-talk during basal ganglia development between Dlx and TGF- $\beta$ pathways based on the overlapping expression of Dlx and activated Smad proteins in the subpallium and the observation that certain Dlx and Smad family members interact in nonneural cells (Chiba et al. 2003; Berghorn et al. 2006). Using both in vivo protein-protein interaction studies and transcription assays in transfected cells, we found that Smad transcription factors physically interact, and co-activate transcription from a telencephalic enhancer, with Dlx proteins. Moreover, chromatin immunoprecipitation studies showed the in vivo localization of both Dlx and Smad proteins to a number of telencephalic enhancers/promoters that are known to be dependent on Dlx1/2 function (Zerucha et al. 2000; Ghanem et al. 2007; Colasante et al. 2008; Potter et al. 2009). These findings strongly suggest that Smad and Dlx proteins participate in common mechanisms during subcortical telencephalon development, shedding new light into the molecular events underlying Dlx function during forebrain development.

Our finding that Dlx $1 / 2 / 5$ and Smad1/2 co-operate to promote transcriptional activation from the enhancer of a telencephalic gene does not appear to result from an increased affinity (or stabilization) of Dlx binding to its DNA target element. EMSA experiments performed using a probe containing a Dlx-binding motif from the mouse Dlx5/ 6 enhancer-i (Zhou et al. 2004) showed that Dlx DNA binding was not affected by co-expression of Smad1, Smad2 or Smad4 (data not shown). It is possible that enhancement of Dlx-mediated transactivation by Smad is the result of a more efficient recruitment of transcriptional co-activators. Potential Dlx co-activators include the PDZ protein, GRIP1 (Yu et al. 2001), Dlxin-1 (Masuda et al. 2001), and Necdin (Kuwajima et al. 2006), while CBP/ p300 transcription factors are believed to be co-activators for Smads (Feng et al. 1998; Janknecht et al. 1998). It should be noted that our observation of a transcriptional cooperation between Dlx and Smad proteins on a telencephalic promoter is in contrast with studies showing that Dlx1/Smad4 and Dlx3/Smad6 interactions result in antagonistic transcriptional effects in non-neural cells (Chiba et al. 2003; Berghorn et al. 2006). For instance, previous studies suggested that Dlx1 interferes with TGF- $\beta$ pathways by binding to Smad4 and sequestering transcriptional co-activators from Smad3/Smad4 heterodimers (Chiba et al. 2003). This discrepancy might be explained by different promoter/enhancer contexts and/or contrasting molecular properties of different Dlx/Smad complexes.

Protein phosphorylation might represent an additional mechanism modulating Smad/Dlx cross-talk. BMP2 stimulation of osteoblasts elicits the phosphorylation of Dlx 5 by the p38 kinase pathway (Ulsamer et al. 2007). Given that
Smads are known to be regulated by various kinase pathways (Massague et al. 2005), including p38 signaling, it is possible that a single extracellular stimulus might regulate the phosphorylation state of both Dlx and Smad proteins and thus synchronously regulate their transcriptional activity. In this regard, our observation that Smad proteins did not enhance transactivation mediated by the DLX5 Ser-Pro and Ser-Arg mutants identified in autistic individuals is intriguing given that serine residues are affected in each case. Future studies are needed to test whether those serines might be kinase substrates. It is also plausible that DLX5 mutants/Smad heteromers fail to recruit the appropriate co-activators.

Role for TGF- $\beta$ signaling in telencephalic GABAergic neuron differentiation

The functional interaction between Dlx and Smads, in addition to the similarities in the expression pattern of Dlx2 and activated Smad2, as well as Gad67 and various components of $T G F-\beta$ pathways, suggested a role for TGF- $\beta$ signaling in GABAergic neuron differentiation. We tested this possibility by performing ex vivo loss of function studies based on the electroporation of dominant negative forms of Smad1, Smad2, and Smad4 in organotypic brain slices. Expression of those dominant negative mutants in the developing basal ganglia phenocopied the defects in tangential migration observed in Dlx1/2-deficient mice. Smad1 and Smad2 dominant negative mutants partially blocked tangential neuron migration, whereas inhibition of Smad4 nearly completely blocked migration. These results suggest that both the BMP/GDF and TGF- $\beta$ / activin/Nodal pathways play a role in that process, resulting in a partial functional redundancy between sub-pathways.

A role for TGF- $\beta$ signaling in GABAergic neuron differentiation is in agreement with the observation that BMP2 promotes survival and differentiation of cultured striatal GABAergic neurons (Hattori et al. 1999) and that BMP6 is a neurotrophic factor for calbindin-positive (GABAergic) striatal neurons (Gratacos et al. 2002). TGF- $\beta$ signaling might also be implicated in the differentiation of other neuronal subtypes in the basal ganglia. This has been postulated for BMP9, which is expressed in the developing striatum and appears to regulate cholinergic neuron differentiation (López-Coviella et al. 2002). It is also worth noting that there is evidence that BMPs regulate expression of $D l x 2$ and $D l x 5$ during bone and feather bud development (Luo et al. 2001; Harris et al. 2003; Kim et al. 2004; Rouzankina et al. 2004; Levi et al. 2006; Liu et al. 2007). While Dlx function may not strongly regulate expression of TGF- $\beta$ signaling components in the embryonic mouse basal ganglia, we cannot rule out that Dlx transcription factors regulate these genes in other tissues. 
In conclusion, the characterization of a functional interaction between Dlx proteins and TGF- $\beta$ signaling pathways is expected to provide new insight into the regulation of the expression of GABAergic phenotypespecific genes. It will also facilitate the characterization of a number of other developmental mechanisms where the expression of members of these protein families overlaps.

Acknowledgements We are grateful to Yasuhiro Kosaka, Nina Kishimoto, Juehu Wang and Michael German for providing the antiDlx 5 antibody. We thank Dr. Edward Ruthazer for his assistance during slice electroporation studies. We also thank Drs. Liliana Attisano, Brian Condie, Rick Derynck, Mark Ekker, Steve Harris, Alexandra Joyner, Seung Kim, Kazuaki Yoshikawa, and Jeffrey Wrana for reagents. This work was supported by a Postdoctoral Fellowship to MM from the Human Frontiers Science Program Organization; and by grants to JLRR (from Nina Ireland, the Larry L. Hillblom Foundation, Cure Autism Now, NIMH RO1 MH4942801, RO1 and K05 MH065670) and to SS (from the Canadian Institutes for Health Research - MOP-13957). S.S. is a Chercheur National of the Fonds de la Recherche en Santé du Quebec.

Open Access This article is distributed under the terms of the Creative Commons Attribution Noncommercial License which permits any noncommercial use, distribution, and reproduction in any medium, provided the original author(s) and source are credited.

\section{References}

Anderson SA, Eisenstat DD, Shi L, Rubenstein JL. Interneuron migration from basal forebrain to neocortex: dependence on Dlx genes. Science. 1997a;278:474-6.

Anderson SA, Qiu M, Bulfone A, Eisenstat DD, Meneses J, Pedersen $\mathrm{R}$, et al. Mutations of the homeobox genes Dlx-1 and Dlx-2 disrupt the striatal subventricular zone and differentiation of late born striatal neurons. Neuron. 1997b;19:27-37.

Anderson SA, Marin O, Horn C, Jennings K, Rubenstein JL. Distinct cortical migrations from the medial and lateral ganglionic eminences. Development. 2001;128:353-63.

Attisano L, Wrana JL, Montalvo E, Massague J. Activation of signalling by the activin receptor complex. Mol Cell Biol. 1996;16:1066-73.

Ayala R, Shu T, Tsai LH. Trekking across the brain: the journey of neuronal migration. Cell. 2007;128:29-43.

Bacchelli E, Blasi F, Biondolillo M, Lamb JA, Bonora E, Barnby G, et al. Screening of nine candidate genes for autism on chromosome $2 \mathrm{q}$ reveals rare nonsynonymous variants in the cAMP-GEFII gene. Mol Psychiatry. 2003;8:916-24.

Berghorn KA, Clark-Campbell PA, Han L, McGrattan M, Weiss RS, Roberson MS. Smad6 represses Dlx3 transcriptional activity through inhibition of DNA binding. J Biol Chem. 2006;281: 20357-67.

Bulfone A, Kim HJ, Puelles L, Porteus MH, Grippo JF, Rubenstein JL. The mouse Dlx-2 (Tes-1) gene is expressed in spatially restricted domains of the forebrain, face and limbs in midgestation mouse embryos. Mech Dev. 1993;40:129-40.

Chiba S, Takeshita K, Imai Y, Kumano K, Kurokawa M, Masuda S, et al. Homeoprotein DLX-1 interacts with Smad4 and blocks a signaling pathway from activin A in hematopoietic cells. Proc Natl Acad Sci USA. 2003;100:15577-82.

Cobos I, Calcagnotto ME, Vilaythong AJ, Thwin MT, Noebels JL, Baraban SC, et al. Mice lacking Dlx1 show subtype-specific loss of interneurons, reduced inhibition and epilepsy. Nat Neurosci. $2005 ; 8: 1059-68$.

Colasante G, Collombat P, Raimondi V, Bonanomi D, Ferrai C, Maira $\mathrm{M}$, et al. Arx is a direct target of Dlx2 and thereby contributes to the tangential migration of GABAergic interneurons. J Neurosci. 2008;28:10674-86.

Consortium IMGSoA. A genomewide screen for autism: strong evidence for linkage to chromosomes $2 \mathrm{q}, 7 \mathrm{q}$, and 16p. Am J Hum Genet. 2001;69:570-81.

Crossley PH, Martinez S, Ohkubo Y, Rubenstein JL. Coordinate expression of Fgf8, Otx2, Bmp4, and Shh in the rostral prosencephalon during development of the telencephalic and optic vesicles. Neuroscience. 2001;108:183-206.

Derynck R, Zhang YE. Smad-dependent and Smad-independent pathways in TGF-beta family signalling. Nature. 2003;425:57784.

Eisenstat DD, Liu JK, Mione M, Zhong W, Yu G, Anderson SA, et al. DLX-1, DLX-2, and DLX-5 expression define distinct stages of basal forebrain differentiation. J Comp Neurol. 1999;414:21737.

Feijen A, Goumans MJ, van den Eijnden-van Raaij AJ. Expression of activin subunits, activin receptors and follistatin in postimplantation mouse embryos suggests specific developmental functions for different activins. Development. 1994;120: 3621-37.

Feng XH, Zhang Y, Wu RY, Derynck R. The tumor suppressor Smad4/DPC4 and transcriptional adaptor CBP/p300 are coactivators for smad3 in TGF-beta-induced transcriptional activation. Genes Dev. 1998;12:2153-63.

Fernandes M, Gutin G, Alcorn H, McConnell SK, Hebert JM. Mutations in the BMP pathway in mice support the existence of two molecular classes of holoprosencephaly. Development. 2007;134:3789-94.

Furuta Y, Piston DW, Hogan BL. Bone morphogenetic proteins (BMPs) as regulators of dorsal forebrain development. Development. 1997; 124:2203-12.

Ghanem N, Yu M, Long J, Hatch G, Rubenstein JL, Ekker M. Distinct cis-regulatory elements from the Dlx1/Dlx2 locus mark different progenitor cell populations in the ganglionic eminences and different subtypes of adult cortical interneurons. J Neurosci. 2007;27:5012-22.

Gratacos E, Gavalda N, Alberch J. Bone morphogenetic protein-6 is a neurotrophic factor for calbindin-positive striatal neurons. J Neurosci Res. 2002;70:638-44.

Hamilton SP, Woo JM, Carlson EJ, Ghanem N, Ekker M, Rubenstein JL. Analysis of four DLX homeobox genes in autistic probands. BMC Genet. 2005;6:52.

Harris SE, Guo D, Harris MA, Krishnaswamy A, Lichtler A. Transcriptional regulation of BMP-2 activated genes in osteoblasts using gene expression microarray analysis: role of Dlx2 and Dlx5 transcription factors. Front Biosci. 2003;8: s1249-65.

Hattori A, Katayama M, Iwasaki S, Ishii K, Tsujimoto M, Kohno M. Bone morphogenetic protein-2 promotes survival and differentiation of striatal GABAergic neurons in the absence of glial cell proliferation. J Neurochem. 1999;72:2264-71.

Hebert JM, Mishina Y, McConnell SK. BMP signaling is required locally to pattern the dorsal telencephalic midline. Neuron. 2002;35:1029-41.

Hebert JM, Hayhurst M, Marks ME, Kulessa H, Hogan BL, McConnell SK. BMP ligands act redundantly to pattern the dorsal telencephalic midline. Genesis. 2003;35:214-9.

Hutcheson HB, Bradford Y, Folstein SE, Gardiner MB, Santangelo SL, Sutcliffe JS, et al. Defining the autism minimum candidate gene region on chromosome 7. Am J Med Genet B Neuropsychiatr Genet. 2003;117:90-6. 
Janknecht R, Wells NJ, Hunter T. TGF-beta-stimulated cooperation of smad proteins with the coactivators $\mathrm{CBP} / \mathrm{p} 300$. Genes Dev. 1998;12:2114-9.

Kim YJ, Lee MH, Wozney JM, Cho JY, Ryoo HM. Bone morphogenetic protein-2-induced alkaline phosphatase expression is stimulated by Dlx 5 and repressed by Msx2. J Biol Chem. 2004;279:50773-80

Kuwajima T, Nishimura I, Yoshikawa K. Necdin promotes GABAergic neuron differentiation in cooperation with Dlx homeodomain proteins. J Neurosci. 2006;26:5383-92.

Levi G, Mantero S, Barbieri O, Cantatore D, Paleari L, Beverdam A, et al. Msx 1 and Dlx5 act independently in development of craniofacial skeleton, but converge on the regulation of Bmp signaling in palate formation. Mech Dev. 2006;123:3-16.

Liem KF Jr, Tremml G, Jessell TM. A role for the roof plate and its resident TGFbeta-related proteins in neuronal patterning in the dorsal spinal cord. Cell. 1997;91:127-38.

Liu T, Gao Y, Sakamoto K, Minamizato T, Furukawa K, Tsukazaki T, et al. BMP-2 promotes differentiation of osteoblasts and chondroblasts in Runx2-deficient cell lines. J Cell Physiol. 2007; 211:728-35.

Long JE, Garel S, Alvarez-Dolado M, Yoshikawa K, Osumi N, Alvarez-Buylla A, et al. Dlx-dependent and -independent regulation of olfactory bulb interneuron differentiation. J Neurosci. 2007;27:3230-43.

Long JE, Swan C, Liang WS, Cobos I, Potter GB, Rubenstein JLR. Dlx1\&2 and Mash1 transcription factors control striatal patterning and differentiation through parallel and overlapping pathways. J Comp Neurol. 2009;512:556-72.

Lopez-Coviella I, Mellott TM, Kovacheva VP, Berse B, Slack BE, Zemelko V, et al. Developmental pattern of expression of BMP receptors and Smads and activation of Smad1 and Smad5 by BMP9 in mouse basal forebrain. Brain Res. 2006;1088:49-56.

López-Coviella I, Berse B, Thies RS, Blusztajn JK. Upregulation of acetylcholine synthesis by bone morphogenetic protein 9 in a murine septal cell line. J Physiol Paris. 2002;96:53-9.

Luo T, Matsuo-Takasaki M, Lim JH, Sargent TD. Differential regulation of Dlx gene expression by a BMP morphogenetic gradient. Int J Dev Biol. 2001;45:681-4.

Macias-Silva M, Abdollah S, Hoodless PA, Pirone R, Attisano L, Wrana JL. MADR2 is a substrate of the TGFbeta receptor and its phosphorylation is required for nuclear accumulation and signaling. Cell. 1996;87:1215-24.

Maddox DM, Condie BG. Dynamic expression of a glutamate decarboxylase gene in multiple non-neural tissues during mouse development. BMC Dev Biol. 2001;1:1.

Maira M, Martens C, Batsche E, Gauthier Y, Drouin J. Dimer-specific potentiation of NGFI-B (Nur77) transcriptional activity by the protein kinase A pathway and AF-1-dependent coactivator recruitment. Mol Cell Biol. 2003;23:763-76.

Marin O, Rubenstein JL. Cell migration in the forebrain. Annu Rev Neurosci. 2003;26:441-83.

Marin O, Anderson SA, Rubenstein JL. Origin and molecular specification of striatal interneurons. J Neurosci. 2000;20:606376.

Massague J, Seoane J, Wotton D. Smad transcription factors. Genes Dev. 2005;19:2783-810.

Masuda Y, Sasaki A, Shibuya H, Ueno N, Ikeda K, Watanabe K. Dlxin-1, a novel protein that binds Dlx5 and regulates its transcriptional function. J Biol Chem. 2001;276:5331-8.

Nakashima M, Toyono T, Akamine A, Joyner A. Expression of growth/differentiation factor 11 , a new member of the BMP/ TGFbeta superfamily during mouse embryogenesis. Mech Dev. 1999;80:185-9.

Ohkubo Y, Chiang C, Rubenstein JL. Coordinate regulation and synergistic actions of BMP4, SHH and FGF8 in the rostral prosencephalon regulate morphogenesis of the telencephalic and optic vesicles. Neuroscience. 2002;111:1-17.

Panchision DM, Pickel JM, Studer L, Lee SH, Turner PA, Hazel TG, et al. Sequential actions of BMP receptors control neural precursor cell production and fate. Genes Dev. 2001;15:2094-110.

Panganiban G, Rubenstein JL. Developmental functions of the Distalless/Dlx homeobox genes. Development. 2002;129:4371-86.

Porteus MH, Bulfone A, Liu JK, Puelles L, Lo LC, Rubenstein JL. DLX2, MASH-1, and MAP-2 expression and bromodeoxyuridine incorporation define molecularly distinct cell populations in the embryonic mouse forebrain. J Neurosci. 1994;14:6370-83.

Potter GB, Petryniak MA, Shevchenko E, McKinsey GL, Ekker M, Rubenstein JL. Generation of Cre-transgenic mice using Dlx 1 / Dlx2 enhancers and their characterization in GABAergic interneurons. Mol Cell Neurosci. 2009;40:167-86.

Rouzankina I, Abate-Shen C, Niswander L. Dlx genes integrate positive and negative signals during feather bud development. Dev Biol. 2004;265:219-33.

Seoane J, Le HV, Shen L, Anderson SA, Massague J. Integration of Smad and forkhead pathways in the control of neuroepithelial and glioblastoma cell proliferation. Cell. 2004;117:211-23.

Shi Y, Massague J. Mechanisms of TGF-beta signaling from cell membrane to the nucleus. Cell. 2003;113:685-700.

Shimamura K, Rubenstein JL. Inductive interactions direct early regionalization of the mouse forebrain. Development. 1997;124: 2709-18.

Stuhmer T, Puelles L, Ekker M, Rubenstein JL. Expression from a Dlx gene enhancer marks adult mouse cortical GABAergic neurons. Cereb Cortex. 2002a;12:75-85.

Stuhmer T, Anderson SA, Ekker M, Rubenstein JL. Ectopic expression of the Dlx genes induces glutamic acid decarboxylase and Dlx expression. Development. 2002b;129:245-52.

Tole S, Ragsdale CW, Grove EA. Dorsoventral patterning of the telencephalon is disrupted in the mouse mutant extra-toes. Dev Biol. 2000;217:254-65.

Ulsamer A, Ortuno MJ, Ruiz S, Susperregui AR, Osses N, Rosa JL, et al. BMP-2 induces osterix expression through upregulation of DLX5 and its phosphorylation by p38. J Biol Chem. 2007;283: 3816-26.

Wonders CP, Anderson SA. The origin and specification of cortical interneurons. Nat Rev Neurosci. 2006;7:687-96.

Yu G, Zerucha T, Ekker M, Rubenstein JL. Evidence that GRIP, a PDZ-domain protein which is expressed in the embryonic forebrain, co-activates transcription with DLX homeodomain proteins. Brain Res Dev Brain Res. 2001;130:217-30.

Yun K, Fischman S, Johnson J, Hrabe de Angelis M, Weinmaster G, Rubenstein JL. Modulation of the notch signaling by Mash1 and Dlx $1 / 2$ regulates sequential specification and differentiation of progenitor cell types in the subcortical telencephalon. Development. 2002;129:5029-40.

Zerucha T, Stuhmer T, Hatch G, Park BK, Long Q, Yu G, et al. A highly conserved enhancer in the Dlx5/Dlx6 intergenic region is the site of cross-regulatory interactions between Dlx genes in the embryonic forebrain. J Neurosci. 2000;20:709-21.

Zhang Y, Feng X, We R, Derynck R. Receptor-associated Mad homologues synergize as effectors of the TGF-beta response. Nature. 1996;383:168-72.

Zhang H, Hu G, Wang H, Sciavolino P, Iler N, Shen MM, et al. Heterodimerization of Msx and Dlx homeoproteins results in functional antagonism. Mol Cell Biol. 1997;17:2920-32.

Zhang Y, Feng XH, Derynck R. Smad3 and Smad4 cooperate with cJun/c-Fos to mediate TGF-beta-induced transcription. Nature. 1998;394:909-13.

Zhou QP, Le TN, Qiu X, Spencer V, de Melo J, Du G, et al. Identification of a direct Dlx homeodomain target in the developing mouse forebrain and retina by optimization of chromatin immunoprecipitation. Nucleic Acids Res. 2004;32:884-92. 